\title{
Teleworking Practice in Small and Medium-Sized Firms: Management Style and Worker Autonomy
}

\author{
by \\ Fintan Clear and Keith Dickson \\ Brunel Business School \\ Brunel University \\ Kingston Lane, Uxbridge, UB8 3PH, UK
}

\author{
Published in \\ New Technology, Work and Employment, 20(3):218-229, Nov 2005.
}

\begin{abstract}
In an empirical study of teleworking practices amongst small and medium-sized enterprises (SMEs) in West London, organisational factors such as management attitudes, worker autonomy and employment flexibility were found to be more critical than technological provision in facilitating successful implementation. Consequently, we argue that telework in most SMEs appears as a marginal activity performed mainly by managers and specialist mobile workers.
\end{abstract}

KEY WORDS: Teleworking, autonomy, management style, SMEs 


\section{INTRODUCTION}

Underlying much popularist thinking and writing on telework is a technological determinist assumption that given the right technology, it is inevitable that teleworking will 'take off'. Toffler (1980) is perhaps the most well-known exponent of this line of thinking, although technology providers have been leading the charge from the outset. According to one prediction made by AT\&T in 1971, 50\% of all Americans would be working from home by 1990 (Sturesson, 1998). While this now looks over-optimistic, telework has for a number of decades been seen by its proponents as a solution to a broad swathe of societal problems. We can take the example of the concern for energy conservation that arose after the 1973 energy crisis - this prompted Nilles (1976) to advance 'telecommuting' (as telework is referred to in the US) as a response at a time when technology was still relatively expensive. Yet, by the end of the $20^{\text {th }}$ Century when technology has dropped considerably in price, is far more advanced, and well supported (at least in industrialised metropoles) by extensive telecommunications infrastructures, telework still does not enjoy anything like the kind of take up in either the USA or the UK as Toffler and AT\&T projected it once would (Gillespie, Richardson and Corford, 1995).

Why is this case? Telework adoption is socially rather than technologically constructed (Huws, 1995; Stanworth, 1997). Other such as Jackson (1999b) argue that social, cultural and political dynamics should not be overlooked in any examination of telework. As a result there has been research which see sees telework as part of a 'virtual organisation' discourse (Stanworth, 1997), and a transport substitute (Illegems and Verbeke, 2003; Mokhtarian and Salomon, 1997). More recently Pyöriä (2003) and Bentley and Yoong (2000) have examined telework as 'knowledge work'. A gender perspective on the subject has been taken by (Beasley, Como-David and Seubert, 2001; Gurstein, 2001) while Baines and Gelder (2003) have focused on the family issues when examining telework. Increasingly a work/life balance discourse is being put forward in relation to telework (see for example, Baines, 2002; Cullen, Kordey, Schmidt and Gaboardi, 2003; Demetriou, Geurts and Kompier, 2004). 
Clearly the adoption and practice of telework is much more than another episode of technological adoption (Jackson, 1999a). Empirical research clearly shows that nontechnical issues hold sway, with the technological determinist position being untenable given the complexities associated with telework adoption and practice.

Despite this telework however is an elusive concept (Qvortrup, 1998; Sullivan, 2003) and there appears to be little definitional agreement on its meaning. Thus Schallabock, Utzman, Alakeson and Jorgensen (2003) cite several dozen definitions of the term in Germany alone. While an all-encompassing definition may be elusive, Illegems and Verbeke (2003) contend that there are five major variables within descriptions of telework, including: a) the amount and proportion of time spent off the employer's premises; b) the location of the work; c) the contractual relationship with the employer (eg employee, contractor); d) the nature of the technology used; e) the nature of the relationship with the employer (eg full-time, part-time).

The purpose of this paper is to examine teleworking practices in small and medium-sized enterprises (SMEs) in West London to explore issues of autonomy and control. Focussing on SMEs is important as much has been written about virtual work and telework in large firms but very little from a small firm or SME perspective. Ward and Shabha (2001) are amongst that minority, looking at questions of motivation, social interaction, isolation and loneliness amongst teleworkers at SMEs in Birmingham. Perrons (2003) and Storey (1997) also deal with some pertinent issues when they focus on SMEs but examine flexible working rather than teleworking as such.

Studying telework in SMEs is important, particularly given how they are described by the European Commission (EC).

20 million SMEs are the backbone of the European economy. They represent 99\% of all enterprises in the EU and provide around 65 million jobs. They create wealth, foster new ideas and are a key source of new jobs. By using ICT and particularly e-business, SMEs have greater opportunities to develop: they are able to buy and sell over the Internet, reduce their costs and boost 
productivity, and manage change more effectively. e-business helps eliminate the barrier of distance, allowing SMEs to trade worldwide from a single website (European Commission, undated)

This quote acts as a rallying cry for telework researchers. The potential to examine new models of working that might ultimately be pervasive amongst such a large constituency explains why the EC funded a 'new methods of work and electronic commerce' theme within its Information Society Technology (IST) research programme (IST, undated).

SMEs are defined by the EC and in the UK as firms employing less than 250 employees with medium firms employing between 50-249 employees, small firms employing between 10-49 employees, and micro firms employing less than 10. This therefore means that of the 4,097,095 enterprises in the UK at the start of 2003, only 8,225 were large (DTI, 2003). Of the SME population 2,870,180 have no employees (DTI, 2003) and as a result there are some 1,226,915 firms employing between 1-249 employees in the UK and it is this group that we drew from for the research reported in this article.

The data used in this paper is the U.K. component of a two year project - the eGap project - which explored telework adoption and practice in 5 European countries. As an IST Framework 5 'Key Action 2' project, eGap ${ }^{1}$ was funded to analyse the reasons why, within specific professional working environments, telework and tele-activities in SMEs face difficulties or meet success in their implementation and operation. The overall objective of the project was to highlight 'best practice' for implementing adequate, positive and sustainable telework practices within SMEs. The purpose of this article is to explore issues of autonomy and control in telework.

\section{WORKER AUTONOMY AND MANAGEMENT STYLE}

${ }^{1}$ IST-2001-35179: further details of the project and its comparative findings can be found at www.egapeu.com. 
Brey (1999: 15) argues that worker autonomy is related to, "the control that workers have over their own work situation", and draws on a definition of job autonomy as, "the worker's self-determination, discretion or freedom inherent in the job, to determine several task elements" (De Jonge, 1995: 13). These task elements include: the method of working, pace of work, procedures, scheduling, work criteria, work goals, the workplace, work evaluation, working hours, kind of work, and amount of work. Thus Brey (1999) argues that worker autonomy refers to the degree to which employees have control over some or all of these task elements.

'Management style' is the overreaching manner in which management exercises control over its workers. A simple model can explore this by contrasting 'Fordist' with 'PostFordist' styles of management, and then considering the implications for worker autonomy. A Fordist style implies strictly prescribed tasks undertaken by subordinatory labour and overseen by a hierarchy of managers and supervisors. Room for workers to exercise discretion in this style is limited as decision making is centralised and hence worker autonomy may be low. A Post-Fordist style on the other hand implies flatter management hierarchies and more flexible and less bureaucratic forms of work organisation (Dimitrova, 2003). Here decentralised decision making allows workers greater discretion over tasks, and hence 'worker autonomy' may be high. If we accept that telework demands some level of organisational flexibility, then it follows that Fordist styles of management will tend to militate against telework. Kodz, Harper and Dench (2002), for example, identify organisational cultures that are incompatible for telework, and whose lack of flexibility is signified within the organisation by unsupportive attitudes, behaviours of managers and colleagues, and a tendency for working long office hours.

Whatever the style of management, forms of control can be many and varied. According to Adami (1999), these are 'direct' controls and 'indirect' where direct controls include direct supervision, quality control, designation of authorisation responsibilities, standard operating procedures, rules, budget and expenditure guidelines. Indirect controls include 
job descriptions, culture, performance appraisals, career development, incentives, compensation and remuneration, training and skills development, and the existence of flexible work arrangements. Direct control of telework is problematic as, at its simplest, teleworking includes two locations: a central office or place where the firm in question is established, and another place remote from the central office (most often the home) where work is undertaken and which by definition is beyond the physical gaze of managers or colleagues.

While many of the rest of Adami's (1999) direct controls can still indeed be exercised, absence of the person physically from the firm's premises means that emphasis may be placed on indirect means of control or what Depickere (1999) refers to as 'input' controls. These focus on organisational culture as a means of leveraging commitment and optimal performance from employees. However she identifies two types of commitment: 'affective' and 'continuance'. The former aims to encourage the individual to find their job and the firm's environment attractive in some measure, while the latter implies costs for the individual to stay in post, or to go elsewhere. Johnson (1998) also examines commitment in a study of control, empowerment and teleworking, and highlights the potential for 'discretionary service behaviour'. This implies that remote workers may exhibit positive or negative behaviour depending on whether they perceive that the psychological contract with their employer is 'intact' or 'breached'. If the latter is the case, then there may be instances of 'tele-shirking' (i.e avoidance of work) and 'imbalanced relationships' (where a teleworker aligns their loyalties more to a firm's customers and/or suppliers than to the firm itself).

This raises the issue of trust between employers and employees with respect to remote working, which is a subject examined by many writers including Huw, Korte and Robinson (1990) and Handy (1995). In a study looking at on-line trust in financial services Knights, Noble, Vurbakia and Willmott (2001) explore how problems of trust and control are managed. They observe how, "a long tradition of management thought conceptualises trust and control as opposing alternatives" (Knights et al., 2001: 313), a dichotomy that they argue is false. To them, trust and control are not necessarily polar 
opposites; rather, they may be complementary, and are combined to varying degrees in everyday working life whether for professionals (who are ascribed as having high levels of trust and low levels of control) or for 'workers' (who are ascribed as having low levels of trust and a high level of control). However, apparent levels of trust may also be contingent on the value of an employee to the firm. For example if someone has irreplaceable skills, then as Adami (1999) attests, methods of control and their magnitude for such individuals may be different from the norm.

Whatever the levels of trust, bargained for or otherwise, firms seeking to exploit telework may need to rethink business processes and working practices in order to take advantage of teleworking. Thus de Leeuw and Volberda (1996) and Pearlson and Saunders (2001) point to a 'flexibility paradox' whereby for teleworkers to have the flexibility to work offsite and to have some level of autonomy in temporal and spatial terms, then the firm must have procedures in place to ensure that the organisation continues to work effectively. So any decision to move towards more flexible working requires structured approaches to business processes. Firms living a 'hand-to-mouth' existence - as anecdotal evidence suggests is the case for many SMEs - and that operate with little forward planning - as is also the case with many SMEs - may find this difficult. If greater structure is required by the firm, then, as Tietze and Musson (2003) observe, this can also be the case for teleworkers who use their home as workplace. This need is amplified where teleworkers share a home with partners and/or children. In this case, additional procedures and practices might be required that separate space and time in the domestic sphere. These issues will be explored using data from the eGap project in the next section of this paper.

\section{THE 'eGAP’ PROJECT AND ITS METHODOLOGY}


The eGap project was, in part, a European response to criticism that there was insufficient empirical data on teleworking practices (Depickere, 1999), especially on a comparative European basis. In each of five regions (one each in Finland, France, Italy, Hungary and the UK), telephone surveys of over 300 SMEs in specified sectors were conducted. These were followed by face-to-face interviews with approximately 60 managers and teleworkers from amongst these firms as well as those with other stakeholders such as regional policymakers and technology providers. Data was also gathered in order to assess whether firm size or sector had a bearing on the adoption of telework, and we used standard European classifications of sector and firm size.

The eGap project definition of telework was, 'working offsite (eg at home, at a customer site, or on the move) whilst linked all day or for some period whilst offsite to a firm's computer systems'. This is a broad definition of telework, and intentionally so as it served to encapsulate the practice in its many forms. Korte and Wynne (1996) are amongst commentators, for example, who do not measure telework of less than one day per week's duration. The eGap definition therefore encompasses all employees that work remotely for however short a period and at whatever location offsite, as long as they have a link to their firm's computer systems. In this way, we intended to capture telework practice in all its forms and without temporal limit.

Whatever the academic debate over telework definitions, on occasion there appeared to be some confusion on the part of survey respondents and interviewees as to the meaning of the term. Throughout the two empirical data gathering exercises, telework was initially misunderstood by some to refer to telesales, and detailed explanation was required therefore to counter this confusion. So, although questions put to respondents were straightforward, the possibility of confusion about the term's meaning persisted and this may be a limitation in this research.

The eGap project focused on the categories D, E, I, J and K of the NACE classification of sector (European Commission, 2002). Definitions for these are shown in Table 1 along 
with numbers of firms falling within the UK survey sample for each. For analytical purposes, categories D and E were aggregated to indicate as 'Industry' (34 firms) while categories I, J and K were aggregated to the category 'Services' (269 firms).

Table 1: Survey sample by sector

\begin{tabular}{|l|l|l|}
\hline & Frequency & Percentage \\
\hline D: Manufacturing & 32 & 10 \\
\hline E: Electricity, gas, steam and water production and supply & 2 & 1 \\
\hline I: Transport, Storage and Communication & 87 & 29 \\
\hline J: Financial Intermediaries & 14 & 5 \\
\hline $\begin{array}{l}\text { K: Business Services (includes real estate, accounting and } \\
\text { legal services, IT services, R\&D and management } \\
\text { consultancy) }\end{array}$ & 168 & 55 \\
\hline Total & 303 & 100 \\
\hline
\end{tabular}

Table 2 shows the sample of the survey population by firm size. Micro firms made up 9\% of the sample, medium firms $19 \%$ and the remaining majority (72\%) were small.

Table 2: Survey sample by firm size

\begin{tabular}{|l|l|l|}
\hline & Frequency & Percentage \\
\hline Micro firms (1-9 employees) & 28 & 9.1 \\
\hline Small firms (10-49 employees) & 217 & 71.7 \\
\hline Medium firms (50-249 employees) & 58 & 19.2 \\
\hline Total & 303 & 100 \\
\hline
\end{tabular}

A telephone survey of 303 firms took place in the six West London boroughs (Brent, Ealing, Hammersmith \& Fulham, Harrow, Hillingdon and Hounslow) making up the UK study region, between December 2002 and January 2003 (Clear, Dickson and Woods, 2003). The sample was selected from a database of over 3000 firms that met the criteria set down by the eGap project. Whilst a few firms in this sample were UK affiliates of overseas interests and therefore were not wholly-independent SMEs, their apparent degree of autonomy was such to justify their inclusion in this study.

In common with the other four regional studies, the survey employed a structured format with 30 questions (many with sub-sections) organised within five major categories - 
adoption and use of information and communications technology (ICT); organisation of work; external links; attitudes to telework; and employment practices. Survey data was captured using SPSS software though no inferential techniques have been used in the statistics presented in this paper.

The survey was followed by 58 face-to-face interviews (May to August 2003), 48 of whom were with business personnel (38 from 'Services' and 10 from 'Industry') and 10 of whom were 'other stakeholders' (policy makers at national, regional and local levels and technology suppliers) (Clear and Dickson, 2003). Detail of the interviewees' firms by size and sector are shown in Table 3.

Table 3: UK Interview Sample by Size and Sector

\begin{tabular}{|l|l|l|l|l|}
\hline & Micro & Small & Medium & Total \\
\hline Industry & 2 & 5 & 3 & 10 \\
\hline Services & 9 & 20 & 9 & 38 \\
\hline Other Stakeholders & \multicolumn{4}{|l|}{} \\
\hline Totals & 11 & 25 & 12 & 10 \\
\hline
\end{tabular}

The overriding majority of interviewees were owner-managers or senior management who were not necessarily IT experts. The bias towards the Services sector can be explained by the fact that manufacturing (as the predominant element of Industry) is not a prominent activity in West London. The interviews were semi-structured and based around core areas of interest related to telework such as telework practice, enablers and/or inhibitors to telework and the effects and/or outputs of telework. The data derived from these interviews were examined using a combination of critical incidents analysis, contents analysis and case study analysis.

\section{THE 'EGAP’ FINDINGS}

Selected findings from the two data-gathering exercise are set out below and discussed on an issue-by-issue basis. They serve to highlight current SME practice in West London in relation to management style and worker autonomy and how these influence telework 
adoption. Other than where noted (such as level of offsite working), size categories did not appear to be prominent to our findings. Additionally analysis by sector was inconclusive. We can surmise that there may be a locational effect operating here as the urban milieu of West London is an expensive location in which to site operations. So whilst listed as manufacturers (and included under Industry), many of these were the office facilities of SMEs rather than their manufacturing plants (which would be located elsewhere). In this way, their function was more akin to Services rather than Industry, therefore suppressing heterogeneity of practice in sectoral terms.

\section{Survey Results}

Several questions in the quantitative study addressed issues relating to the organisation of work such as supervision levels and self-organisation, as these will impinge on telework activities. The responses from these questions are cited below along with further commentary.

Supervision and monitoring of work: The question, "How is work generally controlled in your firm?" sought to identify relative levels of workforce autonomy. Responses, as shown in Table 4, indicate that in a third of the sample work was strictly supervised. The adoption of telework in those firms would be much more problematic than in others with less strict forms of oversight. The very low response to the category 'automated recording of performance' (whereby performance is measured by machine, a potential mechanism associated with telework monitoring) has negative implications here for the relative autonomy of teleworkers.

Table 4: How is work controlled?

\begin{tabular}{|l|l|}
\hline & Percentage \\
\hline Direct supervision & 33.3 \\
\hline Automated recording of performance & 2.7 \\
\hline Work done to specified deadlines & 24.0 \\
\hline Individual goals & 14.7 \\
\hline Team goals & 23.0 \\
\hline Other means & 2.3 \\
\hline
\end{tabular}


Workforce duties: The question, "What kind of duties do you give to your employees?" sought to measure relative levels of workforce autonomy from another angle. Table 5 shows a fairly normal distribution between minimal levels of autonomy ('strict supervision') and maximal levels (defined by 'goals set and organised by the individual'). However the more flexible categories, amounting to over $90 \%$ of respondents, provide some optimism for proponents of telework.

Table 5: What duties are employees given?

\begin{tabular}{|l|l|}
\hline & Percentage \\
\hline Specified duties with strict supervision & 9.3 \\
\hline Specified duties with light supervision & 34.6 \\
\hline Goals set by the individual and achieved to a timetable agreed by a manager & 44.9 \\
\hline Goals set and organised by the individual & 11.3 \\
\hline
\end{tabular}
$\mathrm{N}=301$

Offsite working: Fundamental to telework is the notion of offsite working. In responses to the question (shown in Table 6), "Can any of your staff work offsite during the working day?", just over $75 \%$ replied that they allow such working. Since the sample included distribution firms and professional services, this high score was not surprising. Analysis of responses in terms of firm size (four categories - less than 10 employees, between 10 and 15 employees, between 16 and 30 employees, and above 30 employees) found the larger the firm the greater the likelihood that off-site working was permitted.

Table 6: Off-site working by firm size

\begin{tabular}{|l|l|}
\hline & Percentage \\
\hline Less than 10 employees & 61 \\
\hline Between 10 \& 15 employees & 69 \\
\hline Between $15 \& 30$ employees & 84 \\
\hline Greater than 30 employees & 77 \\
\hline Average for all firms in survey & 75 \\
\hline
\end{tabular}
$\mathrm{N}=303$ 
Self-organisation and flexible working hours: Responses to the question, "Which staff in the firm organise their own working time?" (Table 7), clearly showed a seniority effect. More interestingly, a sizeable proportion of firms (39\%) allowed all staff to organize their own time. Further questioning about flexibility of working hours indicated that only $33 \%$ of sample firms permit flexitime - the opportunity to work flexible hours within set parameters. Of these firms, nearly $76 \%$ operate flexitime for all staff. Taken together these findings suggest there exists a significant cohort of SMEs that have flexible working arrangements that could be a positive influence on telework take-up if those same firms allowed staff to work off-site.

Table 7: Self organisation of working time by seniority

\begin{tabular}{|l|l|}
\hline & Percentage \\
\hline All employees & 39 \\
\hline Senior Managers only & 26 \\
\hline All Managers & 19 \\
\hline All Managers and Supervisors & 3 \\
\hline Nobody & 13 \\
\hline
\end{tabular}
$\mathrm{N}=301$

\section{Qualitative Results}

These issues were further explored in the interviews but first it was necessary to ensure the interviewees understood the meaning of telework. Some interviewees, who initially had stated that there was no teleworking in their firm, changed their mind as the discussion unfolded to cite cases of teleworking colleagues. We can therefore speculate that the proportion of a day spent off an employer's premises and its timing may influence whether or not a colleague is recognised as a teleworker as such. Thus at least some teleworking appears to be 'hidden'.

Another factor that served to hide the practice is that much of the telework examined in the qualitative study was initiated on an informal and voluntary basis. Few formal agreements on teleworking existed, and many of the individuals practising telework were managers who expected to work from home on occasion without this being written into a 
contract. Evidence from Finland (Kurki, Rauhala and Rantala, 2003) shows that some telework was undertaken as a means of catching up on tasks that had not been completed at work. Referred to as 'supplementary telework' (ECaTT, 2000), no formal mechanisms existed to sanction this either.

There were of course teleworkers identified in our qualitative work also worked for lengthy periods of time offsite and were readily identified by interviewees as performing telework. For example, a design director for a small garment manufacturer worked a cycle of one week in the office followed by one week at home. Other teleworkers (mainly senior managers) worked for extended lengths of time offsite whilst on sales or project visits overseas. In the main however those identified as teleworking in our study were part-time teleworkers. This was consistent with Denbigh's (2000) findings that the average time spent teleworking by UK teleworkers was about 1.5 days a week with some period in the week spent working either at or from home, while the other part would include attendance at a central office. For example, in our sample, one insurance firm allowed certain members of its sales staff to be based at home for three days a week and to attend the office for the other two days. Other teleworkers worked from the office, home or elsewhere on a much more ad hoc basis reflecting their particular tasks and schedules. So a number of managers asserted that when they needed peace and quiet to write a report or to digest research, for example, they would generally do this at home in order to avoid disturbances at the workplace.

Planned introduction of telework: In our interviews we found only nine firms (out of the 38 interviewed) had introduced teleworking as a part of a proactive policy-making effort. The majority of these were firms established since 1994 (i.e. after the establishment of the Internet as a business tool) and ones which demonstrated an inclination towards virtual working and telework from the outset. They exhibited advanced use of technology by contemporary standards, and were comfortable working with, for example, interactive whiteboards (by which documents can be seen and annotated by more than one user during a virtual dialogue) and audio or video-conferencing. These users were well aware of what the Internet could offer in communications terms, and exploited it fully to work 
with remote colleagues (and their trading partners) whether over relatively short distances or across the world.

Management style: Outside the apparently forward-looking firms cited as examples above, telework was practised only by a minority of 'workers' in other SMEs, and this minority was overwhelmingly made up of managers and mobile workers who tended to already have levels of autonomy that included offsite working as part of their roles. This is consistent with Felstead, Jewson, Phizacklea and Walters' (2002) findings that the discretion to telework was mainly exercised by managers. Thus telework in such cases only required relatively incremental or supplementary shifts to existing working practices, because flexible organisational arrangements were already in place.

Issues of control: The UK eGap findings did not capture much definitive evidence for the value of 'psychological contracts' as described by Johnson (1998). One interviewee commented that "remote workers see the centre as a bunch of pen-pushers, and the centre sees remote workers as mavericks who appear to feel more in common with trading partners than the firm". This comment seems more a question of classic centre-versusperiphery tensions than telework per se, although telework by definition may suffer from this charge given its somewhat disaggregating thrust. Certainly those interviewees who teleworked appeared happy to do so.

One respondent put forward arguments about the benefits of wholly on-site working for an organisation's health and communications, and felt that the physical disaggregation of employees would naturally lead over time to degradations in internal service delivery. Thus, he claimed, teleworking would inevitably lead to loss of productivity. Another interviewee argued for greater take-up of teleworking but cautioned against introducing telework when existing intra-firm communications were sub-optimal: telework in such scenarios would only exacerbate any communications problems and lead to decline.

In the interviews little focus was placed on electronic forms of performance monitoring. Aside from the necessity of communications to maintain workflow - which is feedback 
on performance in its own right - only two firms used dedicated electronic means to monitor activity at the desktop level. One had a telesales operation selling PCs they assembled, while the other was a US-owned ISP that extended its operations across a number of European countries including the UK and Croatia. Neither firm practised teleworking outside of senior management and neither appeared as 'high trust-based' operations.

Management attitudes: Attitudes of managers and levels of trust they place in employees were particularly influential in the adoption and practice of telework. There was a wide divergence of views, with one well-defined group of interviewees being opposed to telework adoption, and another group favourable to teleworking. Notably the 'protelework' camp were practitioners of telework that believed that such working could enhance productivity, while the 'anti-telework' camp were non-practitioners who felt that telework would only damage productivity. For the latter group, some implied that teleworkers would likely to become 'teleshirkers' when 'out-of-sight', a sentiment echoed in the work of Olson (1988).

Such divergence of view was reported by several interviewees to exist within the same firm. One was the Managing Director of a firm that was part of a three-firm consortium whose working extended over the UK, Germany and the USA. The UK operations used advanced communications tools including audio-conferencing, and the interviewee made clear that he favoured such flexible modes of working. However he also commented that the Finance Director was not keen on such flexible working, preferring instead the traditional mode of onsite working by which he could be sure that effort was being expended on work tasks. Thus managers with quite enlightened, high-trust attitudes towards teleworkers were found alongside managers who had traditional views with lowtrust attitudes that required visual means of control. Diversity of attitudes also prevailed amongst teleworkers themselves, particularly on the more personal issues of the impact of telework on quality of life and work-life balance. 
The strong sentiment expressed by those sceptical of telework that firms would likely lose control over their workers was based for some on personal knowledge of friends or neighbours that teleworked. At least two respondents felt that the term 'working from home' was a euphemism for 'not doing very much' in terms of work tasks. Whilst ostensibly working from home, these teleworkers were as likely to be found - according to these accounts - in the supermarket or doing the gardening rather than at their desks during the working day. Although we do not know whether these reported teleworkers time-shifted and put in working hours outside a 9 am-5 pm envelope, the view persisted that working at home was not as efficient as working in the office.

Worker autonomy: Here we explore the nature of autonomy, how a level of autonomy and teleworking may be bargained for by 'key workers', and the necessity for training for autonomous action if telework is to be successfully extended to non-management or mobile workers.

Differing levels of worker autonomy are reflected in the level of trust held in them by employers. All teleworkers enjoy some level of discretion, by definition, to organize their own affairs. Our taxonomy of teleworkers includes managers, mobile workers, and (other) 'key workers'. Managers by definition enjoy high levels of autonomy as part of their jobs. Mobile sales staff also enjoy some level of autonomy through their being out in the field. Finally, 'key workers' (who are not already managers or mobile workers) can now enjoy a higher level of autonomy that raises the possibility of offsite working due to their valued skills and loyalty.

This last category includes individuals whose roles in the past required entirely officebased working, but for which ICT now offers remote working opportunities. Such employees may be so valuable to an employer that their leaving would pose some level of unacceptable degradation to service quality of the firm's operations (eg in accounts or IT system maintenance, etc). Perhaps difficult to replace, many firms in our sample only extended the possibility of teleworking to such individuals when their loss was inevitable. So rather than a sign of a generalised departure from established custom and practice, 
telework for such employees may be regarded more as an ad hoc reaction to particular circumstances. One IT expert, for example, had managed to negotiate offsite working for two days a week when norms at the firm dictated almost entirely office-based working. The majority of people falling into this latter category of 'key worker' in our sample firms were female. Many had sought teleworking predominantly to better meet care responsibilities for children. After negotiation with their firms, such individuals were in a position to work remotely for part of their working week, or part of their working day, generally from home.

As 'key workers', these teleworkers appeared to have some element of bargaining power with their employer. This was attested to by one owner/manager who had one female employee away on maternity leave when the interview took place. While maternity leave is a statutory right, the offer of flexible working (including telework) is not, even if qualifying employees have had the right to ask their employer for such working since April 2003. This interviewee made clear that he valued this individual for her rapport with customers. He intimated that if she were to ask for flexible working upon return from maternity leave, then he would make a significant effort to accommodate her wishes rather than risk losing her services. Thus telework adoption - at least when applied to those who are not managers or mobile workers - may hinge on the quality of such employees' skills and knowledge.

However, although these individuals enjoyed a level of discretion, such autonomy was conditional. Sales personnel tend to live by targets, as do many managers. Yet any employee may no longer be valued - at least for remote working purposes - if a certain workflow is not forthcoming. As implied by Knights et al. (2001), even highly trusted individuals are under some level of surveillance of work and performance

Autonomy comes with a price. One sales representative (ie non-management) was permitted to base himself at home for most of his work time, and came into the office either once a week or once a fortnight. As a sales representative he lived by sales targets, but was one of two individuals that the shipping firm had decided would have the 
necessary skills and motivation to telework. Nevertheless he felt aggrieved that when given greater access to the firm's systems, he was then expected to update the database with any new prospective clients that he identified during his working day. Each update took at least 20 minutes to complete, something that was previously done by office staff, so he felt that the terms of his job had been changed without his consent, and with some certain element of coercion.

Training: Lorenz, Michie and Wilkinson (1998: 2) observe that "training can be seen as a natural complement to work arrangements that provide increased opportunities for employee participation in decision-making". Such participation has a bearing on the level of autonomy accorded to workers, the 'psychological contract' between employer and employee and would be consistent with the notion that the introduction of new technologies should not be viewed in isolation from other organisational aspects within a firm. As noted earlier, training where it exists in our sample tended to concentrate on 'hard' ICT skills only. Extending telework to non-management ranks, could be problematic as it cannot be taken for granted that individuals possess the necessary spectrum of required skills. Training programmes need to be more holistic in approach by incorporating 'soft skills' such as time management, communication skills, selfactualization, etc. Without adequate training provision, teleworking may be a short-lived experience as a lack of skills leads to restrictions on where and when individuals can work.

\section{DISCUSSION}

In common with other researchers, we found that the term 'telework' open to interpretation, thus making its observation and accurate measurement difficult. Some teleworking in the study was in effect 'hidden' or casual, with certain individuals using 
offsite working to complete tasks, for example, that remained unfinished in the office and/or taking advantage of a locus away from the immediate demands of the office to write reports. Overall, however, outside a small number of exemplary firms, telework in formal terms, was a minority practice, even though enabling technologies such as email (used by over $96 \%$ of the surveyed firms) and Internet (95\%) were very pervasive amongst the surveyed firms. At first sight such figures suggest there are few technological obstacles within the firm to telework adoption, yet clearly the firms have not embraced it to the fullest extent possible. In any event, the data relates to firm usage and does not indicate differential levels of access to ICT by individual employees. So although a firm may use, for example, sophisticated electronic systems for communication between itself and customers and suppliers, this does not imply that all employees necessarily have access to such systems. This argument holds, of course, for all ICT in use in SMEs.

Moreover, personal or home-based ICT equipment and systems are also part of the teleworking equation and differential treatment was evident here also. Therefore, even if remote access was not permitted to a firm's IT systems, electronic communication could be maintained by firms using 'third-party' email accounts such as Hotmail or Yahoo, if so wished. Other teleworkers had remote access to their firm's email system, often in combination with access to data and packages relevant to their function. At least in one case, differential access to data was allowed in combination with generalised access to the firm's bulletin boards and chat rooms. Members of senior management in any event would often have access to a broad swathe of data and packages as part of their responsibilities. The most comprehensive access however appeared to be given to those with 'system's administrator' roles for the firm's system. Generally, these were IT support and development personnel, and in smaller firms these responsibilities were those of senior management/company owners. A few firms used VPNs (Virtual Private Networks) along with firewalls and anti-virus software to defend their intranets which in some cases extended across the globe. In sum, a wide spectrum of ICT sophistication was exhibited by the firms. 
Despite these high levels of technological investment, the cost of associated ICT and concerns about data security were cited as major disadvantages to adopting telework by our surveyed firms (11\% and $20 \%$ respectively of the sample of 276 respondents). But more significantly for this article, the disadvantage cited by the greatest percentage of firms (39\%) was 'absence of employee supervision'. This has obvious implications for the adoption of telework - scepticism about how employees would perform when 'out-ofsight' acted to inhibit telework adoption.

Teleworking was restricted in the main to members of management and sales/maintenance personnel. These were individuals who enjoyed the necessary level of autonomy to work offsite regardless of the provision of ICT in the firm. What was novel however was that an additional set of 'key workers' were also now in a position to telework as a result of the availability of the appropriate ICT. Nevertheless, most members of staff were not permitted to work offsite during standard office hours. This reflects, we believe, a legacy of traditional management styles in which there is a relative lack of trust by managers in their workforces and a preference for visual means of control. This may in part be related to the persistence of hierarchical modes of control and a 'logic of subordination' rather than flatter hierarchies underpinned by a 'logic of collaboration' (Di Nicola, Della Ratta and Como, 2003) which might facilitate the wider adoption of telework by office staff.

In the qualitative study, specific training for teleworking was not mentioned by any of our respondents. Several noted that their firms had training sessions for ICT use, but many of those teleworking already had pre-existing skills which they brought to bear whilst operating remotely. There was little evidence of proactively determined training regimes for those teleworking, and the overall impression was of training done 'on the job'. The dearth of training may be regarded in part as a general failure of SMEs to appreciate the potential advantages that new forms of working (including telework) can bring to their operations. 
Despite the high take up of certain technologies found by the survey we concur with Stanworth's (1997) assertion that "there has been little development of totally virtual organisations, and where they exist, most are found to have been restructured through incremental rather than revolutionary change" (Stanworth, 1997: 55). ICT may be recognised as a key to telework adoption, but it is only enabling - just because an individual has access to such technology as a means of changing work practices, it does not mean s/he will be willing or capable of doing so, even if accorded the permission to try. The UK findings confirm what Nathan, Carpenter and Roberts (2003) observed in other UK firms, that ICT is not transformational in its own right and that there is much sub-optimal use of ICT. The eGap project team agree that, "technological change and organisational structural change (are) concurrent activities that cannot be separated into universals such as shaper and shaped" (Brigham and Corbett, 1996: 69-70). The Italian eGap partner also confirmed the importance of examining wider socio-technical questions stating:

One of the most important results of the survey was to show the close connection between technological and organisational factors: for telework experiments to be successful it is not enough for the work process to be transformable into telework nor the availability of technology for long distance work; an organisational culture orientated towards evaluating results and the promotion of autonomy and responsibility of human resources is also necessary (Di Nicola et al., 2003: 4).

Since ICT ownership is a poor indicator of the likelihood of telework being practised, the eGap team agreed with Moon that, "the real influence on the take-up of telework appears to be at the socio-cultural level, especially the impact of 'supportive' and 'resistant' organisations (Moon, 1998). From an individual perspective, the eGap qualitative study found interviewees to be either 'enthusiasts' or 'sceptics' in regard to telework adoption (Clear and Dickson, 2003). Enthusiasts were those who favoured teleworking, seeing its advantages as outweighing any disadvantages, and who were generally sophisticated users of ICT. Such individuals came from firms of any size or sector, but it was notable that nearly all the interviewees from the newer firms (post-1994) were enthusiasts. 
Seeking to exploit virtual working from the outset, they worked for service providers whose activities were knowledge intensive, and which appeared to have relatively flat reporting structures. 'Sceptics', on the other hand, did not favour teleworking, and saw disadvantages as outweighing any advantages. They could come from any size or sector of firm, and although some of their firms were knowledge intensive in activity (such as solicitors and real estate agents), they were marked more by an essential physicality of activity (such as in logistics).

\section{CONCLUSION}

It is clear from this account that availability of ICT is not the issue when looking for at telework adoption in SMEs. Rather questions at the socio-technical or socio-cultural level hold sway, including attitudes to telework and management style. Thus organisations with strong hierarchies and a management style based on 'the logic of subordination' do not lend themselves easily to any generalised adoption of telework. There appears to be a lack of trust in employees when away from physical oversight with the perception they are less productive when away from work. Only managers and mobile workers - those that have some level of autonomy attached to their roles - are likely to adopt, or be allowed to adopt, telework in such firms. Yet formal mechanisms defining teleworking arrangements are rare because much of it is undertaken on an ad hoc or voluntary basis, in which case its practice may be hidden. The picture is further blurred by a general confusion - even amongst its practitioners - as to what the term 'telework' actually means.

Those firms with flatter hierarchies and which foster 'the logic of collaboration', on the

other hand, appear much more likely to adopt telework beyond managers and mobile workers. Nevertheless there is evidence that 'key workers' (i.e. employees with valuable knowledge and skills, and who are neither managers nor mobile workers) may well be able to telework no matter what the organisational form or prevailing management views due to their personal bargaining power. However the granting of autonomy so that an 
individual can work offsite is not in itself a guarantee of the successful practice of telework. Certainly if there is the desire on the part of SMEs to extend telework to those that are not managers or mobile workers, then training programmes combining 'hard' (e.g. ICT) skills with 'soft' (e.g. communications) skills may be essential.

\section{ACKNOWLEDGEMENT}

The authors wish to gratefully acknowledge the financial support provided by the EC in undertaking work for the eGap project (IST-2001-35179) from which the empirical data in this paper is drawn.

\section{REFERENCES}

Adami, L. (1999), Autonomy, control and the virtual worker, in P. Jackson (Ed.), Virtual Working. Social and Organisational Dynamics, London: Routledge

Baines, S., and Gelder, U. (2003), What is family friendly about the workplace in the home? The case of self-employed parents and their children, New Technology, Work and Employment, $18,3,223-234$

Baines, S. (2002), New technologies and old ways of working in the home of the self-employed teleworker, New Technology, Work and Employment, 17, 2, 89-101

Beasley, R., Lomo-David, E., and Seubert, V. (2001), Telework and gender: implications for the management of information technology professionals, Industrial Management \& Data Systems, 101, 9, 477-482.

Bentley, K., and Yoong, P. (2000), Knowledge work and telework: an exploratory study, Internet Research: Electronic Networking Applications and Policy, 10, 4, 346-356.

Brey, P. (1999), Worker Autonomy and the Drama of Digital Networks and Organisations, Journal of Business Ethics, 22, 4, 15-25

Bringham, M. and Corbett, M. (1996), Trust and the virtual organisation, in P. Jackson and J. van der Wielen (Eds.), New International Perspectives on Telework, Tilburg: WORC 
Clear, F., and Dickson, K. (2003), UK Report for Work Package 2: Telework in UK SMEs - A Regional Analysis of Attitudinal, Organisational and Policy Factors, IST-2001-35179 (www.egap-eu.com)

Clear, F., Woods, A. and Dickson, K. (2003), UK Report for Work Package 1: UK Report of the Survey, IST-2001-35179 (www.egap-eu.com)

Cullen, K., Kordey, N., Schmidt, L., and Gaboardi, E. (2003), Work and Family in the eWork Era, Amsterdam: IOS Press

De Jonge, J. (1995), Job Autonomy, Well-Being and Health: A Study Among Dutch Health Workers, Universitaire Pers Maastricht, Maastricht

De Leeuw, A., and Volberda, H. (1996), On the concept of flexibility: a dual control perspective, International Journal of Management Science, 24, 2, 121-139

Demerouti, E., Geurts, S., and Kompier, M. (2004), Positive and negative work-home interaction: prevalence and correlates, Equal Opportunities International, 23, 1, 6-35

Denbigh, A. (2000), The Teleworking Handbook, 4e, London: A \& C Black

Depickere, A. (1999), Managing virtual working: between commitment and control? in P. Jackson (Ed.) Virtual Working. Social and Organisational Dynamics, London: Routledge.

Dimitrova, D. (2003), Controlling teleworkers: supervision and flexibility revisited, New Technology, Work and Employment, 18, 3, 181-195

Di Nicola, P., Della Ratta, F., and Como, E. (2003), Qualitative Analysis of Interviews in Emilia Romagna, eGap IST-2001-35179 (www.egap-eu.com)

Department of Trade and Industry (2003), SME Statistics UK 2003, http://www.sbs.gov.uk/default.php?page=/analytical/statistics/smestats.php (accessed 2006-05)

ECaTT (2000), Benchmarking Progress on New ways of Working and New Forms of Business Across Europe: Final Report, IST Project (www.ecatt.com)

European Commission (2002), Statistical Classification of Economic Activities in the European Community, Rev. 1.1,

http://europa.eu.int/comm/eurostat/ramon/nomenclatures/index.cfm?TargetUrl=LST_NOM DTL\&StrNom=NACE 1 1\&StrLanguageCode=EN\&IntPcKey $($ accessed 30-06-05)

European Commission (undated), SMEs and the ICT Challenge: A "Think Small First" Approach, 'IST Thematic Portal' http://europa.eu.int/information_society/ecowor/smes/index_en.htm (accessed 30-06-05) 
Felstead, A., Jewson, N., Phizacklea, A., and Walters, S. (2002), The option to work at home: another privilege for the favoured few?, New Technology, Work and Employment, 17, 3, 188-207.

Gillespie, A., Richardson, R., and Cornford, J. (1995), Review of Telework in Britain: implications for public policy, Newcastle Programme on Information and Communications Technologies, CURDS, University of Newcastle upon Tyne

Gurstein, P. (2001), Wired to the World, Chained to the Home, Vancouver: UBC Press

Handy, C. (1995), Trust and the virtual organisation, Time Magazine Special Edition May-June: 40-50

Huws, U. (1995), Social Europe: Follow up to the White paper - teleworking, European Commission DGV. Office for Official Publications of the European Commission

Illegems, V., and Verbeke, A. (2003), Moving Towards the Virtual Workplace, Cheltenham: Edward Elgar

Information Society Technology (undated), Key Action 2 - New Methods of Work and

Electronic Commerce, 1998-2002, European Commission, http://www.cordis.lu/ist/ka2/welcome.htm (accessed 23-06-05)

Jackson, P. (1999a), Introduction: from new designs to new dynamics, in P. Jackson (Ed), Virtual Working. Social and Organisational Dynamics, London: Routlege

Jackson, P. (1999b), Organisational change and virtual teams: strategic and operational integration, Information Systems Journal, 9, 4, 313-332

Johnson, S. (1998), Teleworking service management. issues for an integrated framework in P. Jackson and J. Van Der Wielen (Eds) Teleworking: International Perspectives, London: Routledge.

Kodz, J., Harper, H., and Dench, S. (2002), Work-Life Balance. Beyond the Rhetoric, IES Report 384, Brighton: IES

Korte, W., and Wynne, N. (1996), Telework: Penetration, Potential and Practice, Amsterdam: IOS Press

Knights, D., Noble, F., Vurdbakia, T., and Willmott, H. (2001), Chasing shadows: control, virtuality and the promotion of trust, Organisation Studies, 22, 2, 311-366.

Kurki, M., Rauhala, T., and Rantala, S. (2003), Report of eGap Qualitative Phase for Tampere Region, eGap IST-2001-35179 (www.egap-eu.com)

Lorenz, E., Michie, J., and Wilkinson, F. (1998), DARES (the Studies and Statistics Division of the French Labour Department), Familles Professionnelles, données de cadrage (Job families, framework data), Paris 
Mokhtarian, P., and Salomon, I. (1997), Modeling the desire to telecommute: The importance of attitudinal factors in behavioral models, Transportation Research, 31, 1, 35-50.

Moon, C. (1998) Factors affecting the take-up of teleworking in the UK, in R. Suomi, P. Jackson, L. Hollmen, and M. Aspnas (Eds), Teleworking Environments: Proceedings of the Third International Workshop on Telework, September, Turku, Finland.

Nathan, M., Carpenter, G., and Roberts, S. (2003), Getting by, Not Getting On, London: Work Foundation.

Nilles, J (1976) Telecomunications-Transportation Tradeoff: Options for Tomorrow, New York: Wiley.

Olson, M. (1988) Organisational barriers to telework, in W. Korte, W. Steinle and S. Robinson (Eds), Telework: Present Situation \& Further Development of a New Form of Work, Amsterdam: North-Holland

Pearlson, K., and Saunders, C. (2001), There's no place like home: managing telecommuting paradoxes, The Academy of Management Executive, 15, 2,117-128.

Perrons, D. (2003), The New Economy and the Work-Life Balance: Conceptual Explorations and a Case Study of New Media, Gender, Work and Organization, 10, 1, 65-93

Pyöriä, P. (2003), Knowledge work in distributed environments: issues and illusions, New Technology, Work and Employment, 18, 3, 166-180

Qvortrup, L. (1998), From teleworking to networking: definitions and trends, in P. Jackson and J. Van Der Wielen (Eds) Teleworking: International Perspectives, London: Routledge.

Schallabock, K., Utzman, I., Alakeson, V., and Jorgensen, B. (2003), Telework and sustainable development, DEESD - IST Programme, http://www.forumforthefuture.ork.uk/uploadstore/GeSI_case_study.pdf (accessed30-06-05)

Stanworth, C. (1997), Telework and the information age, New Technology, Work and Employment, 13, 1, 51-62

Storey, J. (1997), Radical change or business as usual: Flexibility in non-union SMEs, International Journal of Entrepreneurial Behaviour and Research, 3, 3, 157-167.

Sullivan, C. (2003), What's in a name? Definitions and conceptualisations of teleworking and homeworking, New Technology, Work and Employment, 18, 3, 158-165

Sturesson, L., (1998) The mis-match between suppliers and users in telework, in P. Jackson and J. Van Der Wielen (Eds) Teleworking: International Perspectives, London: Routledge.

Tietze, S., and Musson, G. (2003), The times and temporalities of home-based telework, Personnel Review, 32, 4, 438-455

Toffler, A. (1980) The Third Wave, London: Collins 
Ward, N. and Shabha, G. (2001), Teleworking: an assessment of socio-psychological factors, Facilities, January, 19, 1-2, 61-71. 